\title{
Failure to establish a persistent response producing a net loss in reinforcement
}

\author{
DAVID LEVINE ANO EUGENE F, MALESKI \\ UNIVERSITY OF NEBRASKA
}

Sixteen rats, food-deprived for $23 \mathrm{hr}$. and trained on 29 trials to a median running time of 3 or less sec., failed to run over a large pile of wet mash to reach a goal box containing $.20 \mathrm{gm}$ of wet mash. The position of the food box in the alley had no effect on the response. The results are interpreted as evidence against the generality of a theory of persistent response sequences.

Stolz \& Lott (1964) report that rats, trained to run an alley for food, will continue to run to the goal box even on trials in which they encounter a pile of pellets on their way to the goal. Stolz and Lott report their Ss ran over a 6 in. long $\times 1 / 2$ in. deep pile of pellets for a single pellet in the goal box for many trials before a criterion of eating 30 pellets in the alley was reached. They report that the amount of training had no effect on the number of trials to criterion. Mandler (1964) interprets this finding as support for his position that once a response is organized it will tend to persist even in the face of disruptionproducing interruptions. He would predict that the tendency to persist would be stronger the greater the length of the response sequence prior to interruption.

The present study is an attempt to investigate further the generality of the statement that "organized behavior persists even after a premature encounter with an anticipatory goal" (Mandler, 1964, p. 196). Method

A total of 16 male Holtzman rats, 79 days old at the beginning of training, finished the experiment. Four Ss were discarded: three for not running and one due to injury resulting from an apparatus malfunction. Each $S$ was housed in an 8 in. $x 8$ in. $x 11$ in. cage: Wayne lab blocks and water were available ad lib for 10 days after which the Ss were put on a 23-hr. deprivation schedule when they were fed wet mash.

Training. An alley with a screen bottom and top and wood sides, 78 in. long $x$ 5-7/8 in. high $\times 8-1 / 2$ in. wide, separated from a 12 in. $x 12$ in. $\times 5-7 / 8$ in. goal box and $a 11$ in. $x 11-1 / 2$ in. $x$ 5-7/8 in. start box by guillotine doors, was used for the experiment. A food cup, like the one used to feed the Ss in their home cages, was fastened to the side of the goal box. On the eleventh and twelfth days of the deprivation schedule, each $S$ was handled for $15 \mathrm{~min}$. and allowed to explore the apparatus for $15 \mathrm{~min}$. On the thirteenth day of deprivation, reinforced training of Ss in the alley began. On each trial (both training and test) the reinforcement consisted of approximately $.20 \mathrm{gm}$ of dry mash mixed with one or two drops of water. After each trial $S$ was placed for at least $30 \mathrm{sec}$. in a holding cage with a water bottle. However, no $\mathrm{S}$ was ever observed to drink at any time in this cage. The Ss were run in the same order and were fed at the same time each day, with no $S$ being fed until at least 15 min. after running.

All Ss were trained five trials a day for three days and then 11 trials a day until they reached a criterion asymptote of median running time (time from leaving the start box until entering the goal box) of $3 \mathrm{sec}$. or less on an 11-trial day. All Ss reached asymptote on the first 11-trial day with 14 of 16 Ss having median running times of $2 \mathrm{sec}$. or less.

Test Trials. On the test day (the second 11-trial day) each S was given three "warm-up" trials and then a food box was placed in one of three places: (a) 4 in. from the start box door; (b) in the center of the alley; (c) 4 in. from the goal box door. The food box had outside dimensions of $7-3 / 16 \mathrm{in}$. width $\times 2-1 / 16$ in. length $\times 2-5 / 16$ in. depth and inside dimensions of $7-1 / 4$ in. $x 1-1 / 2$ in. $x 2$ in. In other words, it covered the entire width and less than half of the depth of the alley; the food was piled about $1 / 4$ in. over the top. If the $\mathrm{S}$ did not reach the goal box within $5 \mathrm{~min}$. on any trial, he was removed from the alley and terminated. If $S$ did reach the goal box, he was not removed until he ate the food there; then he was held in the holding cage for at least $30 \mathrm{sec}$. and run again up to a maximum of eight trials (or a total of 11 trials for that day).

\section{Resulfs and Discussion}

The most impressive result is that all animals stopped and ate at the food box on the first test trial. Furthermore, unlike Stolz \& Lott's (1964) findings, nine of the 16 Ss never reached the goal box in the $5 \mathrm{~min}$. allowed. Two Ss ran to the goal box once; one $S$ ran twice; and only four Ss ran the maximum allowed eight times. Even the Ss that jumped over the food did so after eating and, to E, their behavior more closely resembled exploratory behavior which eventually got them to the goal box, in contrast to the rapid goal-directed behavior observed prior to the test trials. Of a possible 300 sec. eating time on the first test trial, the mean eating time for 16 Ss was $177.7 \mathrm{sec}$. and the median was $220.5 \mathrm{sec}$. In other words, the mean S spent $59.2 \%$ of the allowed time eating; the median $\mathrm{S}$ spent $73.5 \%$ of the allowed time eating. This behavior does not seem to resemble a persistent 
response to ignore the food in the alley and to continue to run to the goal box for the much smaller reinforcement. The position of the food box in the alley had no effect on this behavior ( $d f=2 / 13, F=.2297$ ).

The theory of persistent organized response sequences suggested by Mandler (1964) does not seem relevant to behavior in this situation. Perhaps the difference between these results and those of Stolz \& Lott (1964) can be explained on the basis of attention, i.e., forcing the Ss to attend to the anticipatory goal. Rats running as fast as those in this study could more easily run over a $1 / 2$ in. pile of pellets (used by Stolz and Lott) without noticing them than over a 2-9/16 in. pile of wet mash in a box. Furthermore, the mash emitted a strong odor which was easily detectable by $\mathrm{E}$ four feet from the alley. It seems that more research is needed to investigate the limitations under which persistent behavior does occur. Perhaps persistence toward completion of a response is a function of the stimulus characteristics of the alternate, more rewarding, state of affairs.

\section{References}

Mandler, G. The interruption of behavior. In D. Levine (Ed.), Nebraska symposium on motivation. Lincoln, Nebraska: University of Nebraska Press, 1964. Pp. 163-219.

Stolz, Stephanie B., \& Lott, D. E. Establishment in rats of a persistent response producing a net loss of reinforcement. $J$. comp. physiol. Psychol., 1964, 57, 147-149. 